\title{
Not Only the Sorcerer's Apprentice: Re-Conjuring the Ph.D.
}

\author{
Kristy Buccieri \\ York University \\ Campbell McDermid \\ York University \\ Joy Mannette \\ York University
}

\begin{abstract}
Without a magic mirror on the wall, Ph.D. students have to look elsewhere for answers. In this paper, we pose the question, "What does it mean to be a Ph.D. in the $21^{\text {st }}$ century?" We explore this issue through our respective social locations, as two first year Ph.D. students from differing backgrounds and as a tenured professor in a Faculty of Education. Our interest lies beyond a critique of the current model and a dualistic consideration of what should or should not be. Instead, we engage auto-ethnography with an analytic-induction approach to consider what postmodern doctoral studies might entail. The discussion is informed by a range of theorists, allowing us to consider multiple voices in the process of inculcation within the canon. Central to our discussion is the motivation of doctoral students and the means by which we can find our place within existing research communities. We examine the responsibility of students in animating knowledge and disseminating it outside the walls of the established academy. With a $\mathrm{Ph} . \mathrm{D}$. comes considerable power. The time has come for us to re-think the way we pass the wand from sorcerer to apprentice, and perhaps, even what constitutes the wand.
\end{abstract}

This paper is the product of an on-going thought exercise among two first year Ph.D. students and a tenured professor within the discipline of Education. We began by asking: "What does it mean to be a Ph.D. in the 21 st century?", "What is the motivation of doctoral students?" and "By what means do we make our place within existing research communities?" As you will see, it has turned into a conversation that extends far beyond these questions. If, as Thomas King (2003) adjures, "The truth about stories is that that's all we are" (p. 2), we are as the Mi'kmaq say, Na te'lioq.

As a means of conceptualizing the structure of this paper, we will begin with a discussion of our "research questions," a brief narrative that attempts to document what led us to this process of auto-ethnography and the construction of this manuscript. As a methodology we frame our discussion based on Rogers' 
(1969) post-modern re-conceptualization of graduate studies, Wenger's (1998) Communities of Practice, and Lave's (1990) culture of acquisition. In our concluding remarks, we resist an empiricist view of research as determinate and "truth" finding, even if highly contextualized and admittedly subjective, by keeping the focus on the process "of becoming."

\section{Ghosts, Identities, and Questions: Two Students and One Ph.D.}

Kristy: As a perpetual student, I am very familiar with "the look" people give me when they ask what I do for a living. It is the tilted head and the scrunched eyebrows that silently ask, "When are you going to join the real world?" This question always puzzles me. If I am not living in the 'real' world-where am I?

Campbell: When I asked myself what it meant for me to become a Ph.D. student, I took a different approach than Kristy's approach. This might be due to our different backgrounds: hers in Sociology and mine as a college professor with a background in Psychology. My thoughts also benefited from our collaboration with Joy, who helped frame some of my questions. I wondered how does one balance the role of passive knowledge learner and deferent novice, while also adopting the persona of knowledge creator and expert? Why is it that graduate study requires its doctoral candidates as "empty vessels" who must be canonically filled? What is lost and gained in programmatic insistence that students do not know and professors do. As graduate students, to what extent are we expected to inculcate within ourselves the canon of Education, and what amount of personal transformation at the level of epistemology and axiology is required to succeed? What does it mean to succeed other than reproduce what is?

Further, in an interdisciplinary applied field, what might reasonably be defined as canonical? How can I understand the notion of canon in relation to the ideological precepts of those professors, whose knowledge stands over and directs mine and that of other doctoral candidates? What identities must we perform à la Butler (1999), and shed as we make our way through the process of doctoral studies? Such are the challenges and the paradoxes of graduate student identity formation.

Joy: What is this "passing the wand" business and how am I implicated? When I think of the sorcerer's apprentice, and apologies to Dukas (Disney, 2009) and to Mendelssohn, I think about Fantasia. It seems that I can conceive of myself as a sorcerer and Campbell and Kristy as apprentices only in irony. It is an illusion that I, as sorcerer-professor "make" the magic but it is that illusion which animates graduate studies and the difficult relations between doctoral candidates-apprentices and the assumed magicians.

In Mickey's cosmology, in the absent-presence of the sorcerer, the apprentice Mickey Mouse thinks about working the master's magic. He had studied the signs and portents and is determined. Just look at him; he is going to get that mop to do the pesky chores. The Disney-fication of Western childhoods means that most of us reared in this way know how the story unfolds, with a much chastened apprentice who learns to his chagrin that he is not ready to wend the wand. And if I had trouble thinking about what is the wand, and how I ought to endow it upon doctoral candidates, I become even more troubled by the notion of "readiness." 
Campbell: In the fall of 2007, by beginning full-time doctoral studies I willingly put myself on the path to becoming the sorcerer's apprentice and to unknowingly confronting my identity reformation within the context of graduate studies. At that time, I had the opportunity to take a class entitled "Paradigms: Ways of Knowing," hereafter referred to as "Paradigms," with my two coauthors, Joy, the course professor, and Kristy, a peer in the doctoral program.

Almost immediately our discussions turned to graduate student identity formation, a dialectic facilitated by the very nature of a course examining paradigms. I often left class wondering if I considered myself a member within a community and to what extent had I become invested in, or disenfranchised from, academia? I wrestled with the discourse of Education as something transient to me, a persona to take on and then later discard once my studies were completed. How could I claim ownership of my own, seemingly tentative work, and in the same breath responsibility for mastery in this field? Why did I see the Ph.D. as something to get through, not something to enjoy?

Even trivial administrative details such as course selection took on new life as I began to question why I felt anxiety about classes that appeared written to challenge my personal paradigm. Further, I hesitated to design an independent study course in my area of interest, ASL and Deaf culture. Why did some courses, such as the Doctoral Seminar have more significance than others? How could I bear simultaneously to inculcate and deconstruct the canon? (Joy: How is it that the perennialist, essentialist pedagogy rendered him publicly unsure?). I was also engaged in an internal dialogue concerning a multitude of other issues, such as the nature of supervision. How could I build a supportive relationship with my supervisor without relying on her to such an extent that I became a burden? I also wondered if my reflections were in any way similar to the experiences of other graduate students and their identity formation. It was hard to tell.

\section{Methodology}

To guide the reflective process we used for this paper, we turned to our summative project from the Paradigms course. Our methodology was autoethnographic in nature and made use of a layering technique to create a pastiche or bricolage of our experiences. The benefit of this process was the ability to express our own unique positionalities, but there were times when the conversation was divergent. This might unsettle the reader as the fourth, subsequent voice in this dialogue.

In Paradigms, the epistemological foundation of this layering process was the selection of quotations from a number of texts we studied and then a representation of themes that were important to us, ranging from collages, papers, and a pastiche created by Kristy. In the creation of this manuscript we layered our thoughts and experiences and a number of other resources such as conversations with our peers, notes we had made concerning our own growth since our admission into the program, and visual representations from the Internet. Through reflection, we hoped to identify embodied patterns in our thinking and sought to discover our personal paradigms.

We identified an article by Haig-Brown and Dannenmann (2002), entitled "Pedagogy of the Land: Dreams of Respectful Relations," in which the authors 
demonstrated how their distinct reflections and textual contributions could be interwoven to produce an authentic representation of the lived experiences of both writers. We borrowed this technique of alternating writers and identifying speakers to show how our viewpoints differ and yet work to complement the voice of the other. As Haig-Brown and Dannenmann (2002) pointed out, the discourse of academia relies, "almost exclusively on text" (p. 454) and assumes one and only one authorial voice. The creation of this document serves as a means of challenging that by facilitating a dialogue between the authors.

A second piece that we drew inspiration from was "Experience Research Social Change: Methods beyond the Mainstream" by Kirby, Greaves and Reid (2006). In it, the authors described the process of collaborative research and raised issues of authentic negotiated participation, identify formation, and ethical inquiry. As we three authors engaged in discussion and text creation, we were haunted by the advice of Kirby et al. (2006) who wrote, "It is also important to question who is participating, why they are participating, to what degree and in what phase of the project they are participating, and where the true power lies" (p. 44).

\section{Postmodernism and the Culture of Acquisition}

Kristy: Jean Lave (1990) writes that in the "culture of acquisition" view of learning, school is viewed as the institutional site for decontextualizing knowledge. This means that abstracted, it may become general and generalizable. As Ph.D. students, we are expected to take the knowledge we learn and use it once we enter the 'real' world. What bothers me is that we are asked to position ourselves within this binary - where the learning process and the knowledge we gain from it are "here" and the world in which we are to apply it is "over there". How did it come to be that we think this way? What can be done to change this?

Lesko (2001) writes that the human being of postmodernism is to be understood as a text, as a composition, as a bricolage, or as a performance without an essential core. This surely is challenging to all involved. The traditional approach to education-it seems to me-has always had the underlying pedagogical goal of producing complete beings. That is, you go in a child and come out a responsible young adult ready to enter that pesky 'real world'. Education has always been a way to fill in gaps, provide the learner with answers, and give them more knowledge than they had before. How do we rectify this with the postmodern student who becomes increasingly fragmented as s/he learns? Tearing down preconceived notions and looking at the world in new ways is not an easy thing to do. How can fragmented persons contribute anything? How can we get past the mentality that learning has an end point at which we are complete?

Joy: The doctoral candidate-apprentice who is required to labour in relation to the tenured professor is also a knower, though not in the same way to the sorcerer-professor in whose likeness s/he should never be self-molded. This is an ethical question. I am one with Simon, Rosenberg, and Eppert (2000) who query, what (if anything) beyond empathy is the disposition of knowing with respect to the Other? Post-colonial theorizing by Others now in the academy has forced professors almost to the point of research paralysis, until we hit upon dubious 
notions of equity and inclusion which have forced the hegemonic academy to embrace, while marginalizing Otherness (see, Dlamini, 2006; Graveline, 1998).

\section{Enter Jean Nicolas}

Joy: Back to Mickey, the sorcerer is away; supervisors and committee members are often "away"-_sometimes literally but more so symbolically in that we make ourselves and our insights unavailable due to our preoccupations with our own legacy, (other) committee work, service and teaching obligations, and increasingly a sense that we just cannot keep up in the market-driven university (Turk, 2008). Part of this performance anxiety is complicated by the relation with the doctoral candidates who will inevitably supplant us. In so doing, we are rendered redundant in the magic-making business in which we actively and avidly participate.

Kristy: But will we make you redundant? In "Researchers for tomorrow" Nicolas (2008) argues it is time we re-think the way we do $\mathrm{Ph} . \mathrm{D}$. training. In Canada, he notes, two out of three Ph.D. graduates will not become university professors. Where do they end up? According to Nicolas, they take up positions in society. In other words, they go to the "real world." If the culture of acquisition view of learning is correct - that we teach people in school to prepare them for life outside school - then recent Ph.D. graduates should be excelling in the workforce. This, according to Nicolas, is not the case.

Campbell: As a college instructor, I guess I am one of those individuals in the "real world." Nicolas (2008) argues that students were in fact not being prepared for positions such as my own, and congruent to Lave's (1990) model of a culture of acquisition, programs insist on maintaining traditional pedagogies (Nicolas, 2008). Future researchers therefore continue to be educated within an epistemology premised on a model of "in-and-through research" or "apprenticeresearcher" (Nicolas, 2008). This process is designed to culminate in the "transformation of students from users into creators of knowledge," from dependent to independent professionals (Nicolas, 2008, p. 2). Success is defined as "The ability to formulate original and important questions or hypotheses, to reconfigure and adapt complex or advanced knowledge, and to solve new problems" (p. 3). I am not sure how this model addresses the professional requirements of a college instructor.

Kristy: Given the belief in apprentice-researcher, I wonder what we can do to ensure that what we are trained for is the same as what is needed. We cannot deny that our world has changed and is still changing. If we want to produce quality graduates we must take the time to consider how we educate them. It is not enough to consider the school's responsibility-we must also challenge the student's ability to engage within a different pedagogical paradigm. Living in a rapidly changing world makes it evidently clear that learning is not something that happens before a person enters the real world - it is not a state but a process. As the researchers of tomorrow, graduate students hold a responsibility to society to take what they learn and apply it as they learn it.

Campbell: I believe that others feel the same way. Nyquist and Wulff (2002), for example took up similar issues, as they urged institutions to help create "scholar-citizens who see their special training connected more closely to the needs of society and the global economy." They encouraged program design that 
maintained a balance between specialized and interdisciplinary studies and which fostered "partnerships with all involved in doctoral education." One means of doing this, according to Nyquist and Wulff (2002) was "exposure to a wide variety of career options" for doctoral applicants.

\section{Re-Conjuring Carl Rogers}

Kristy: Noted psychologist Carl Rogers (1969) grappled with similar questions about graduate education. He published a book entitled, "Freedom to Learn", in which he outlined his concerns about doctoral training. While his critique of the current program is interesting, it is his proposal in the chapter "A Revolutionary Program for Graduate Education" that I wish to discuss. When it was written, it was shunned by the world of academia for being too radical. Today, we would call it postmodern.

When I try to imagine a postmodern approach to graduate studies, it looks very much like the program Rogers (1969) envisioned. He argued that the student should be free to use a four year period to experience his/her chosen field and to engage in meaningful learning. In this system, there are no required classes and grades do not factor into the evaluation criteria. Students have resources available to them, such as faculty members, libraries, clinics, and labs but must earn permission to use them. Learners are called upon to create, facilitate, and monitor their own programs. At the beginning of each semester the student submits a tentative plan of what $\mathrm{s} / \mathrm{he}$ hopes to accomplish over the next several months. When the semester is finished s/he must submit a progress report. At the end of the four years, the student gives his/her committee of university and external academics a portfolio of work. To earn a doctoral degree the student must be able to show his/her contribution to knowledge, professional competence, and breadth of learning.

Campbell: I would consider Rogers' (1969) book both seminal and prescient for its time, 1969! Could this debate actually have been going on for nearly forty years?

Kristy: Amazingly yes! Rogers (1969) was concerned not only with how graduate programs operated but with their entrance criteria. He listed three criteria for admission to this type of program - intelligence/ability to problemsolve, empathic understanding, and a childlike curiosity. Is meeting all of these requirements the same as being a postmodern student? The beauty of this model is that there is no answer; it erases the need for the "perfect" student. To do well, one has to open his/her mind, ask questions, and actively seek answers.

Campbell: The selected candidates would then assume a role as active and junior participants in a community of practice, the foundation of Rogers' (1969) epistemological approach and a concept we will address later in this paper. His conception of education was that of a progression of becoming, as Kristy has noted earlier, thus process oriented and social and relational in nature.

Kristy: Here we have a proposed model of graduate training that opens up many possibilities for engaging in knowledge and learning in a meaningful way. It is difficult not to get excited about directing the course of one's own learning. Recall the thrill of being a child and how you wanted to know everything about everything. The questions of "why" and "how" are often lost as we get older. In graduate school we are specifically trained not to ask questions like, "why does 
such and such happen?" They are often seen as too simplistic. Yet, to truly understand something - to get to the core - we need to start with the questions of "why" and "how."

Rogers (1969) writes that the major purpose of the program is to set up an environment in which freely self-directed and creative learning can take place. It seems to me that there is a very close relationship between creativity and the kind of questions we allow ourselves to ask. If we do not let the childlike questionsthe "whys" and "hows" - into our studies we run the risk of getting stuck. Rogers (1969) tells us that his program is primarily oriented toward the future problems of one's science and profession rather than its past history or present accumulation of so-called "facts." If, as Nicolas (2008) argues, we are living in a knowledge-based economy and the job market is changing, we have to prepare ourselves for it. As Rogers (1969) describes it, his program will prepare students to enter into a changing world.

Campbell: Here I want to talk about the concept of hybrid identities in an ever-changing postmodern world and share an example of "new" knowledge. With the advent of the Internet and specifically streaming technologies like YouTube, there are an increasing number of ways of sharing information about ASL and Deaf culture. At the same time, cultures and languages are being blended and new hybrid possibilities are emerging.

In a video by Deaf Performing Artist Network (DPAN, 2009), you can see how they have taken the song "Waiting on the World to Change" by John Mayer and translated it into ASL. This translation speaks to both a hearing and Deaf audience and lends itself to multiple interpretations. By streaming the video on the Internet, it makes it present and lends authenticity to it to a global audience. More importantly, by blending something from the non-Deaf hearing world with a performance in ASL, it acts to instil a sense of awareness of ASL as a language of performance and of the need to remake the world to include a Deaf identity.

Kristy: This video is an excellent example of what Rogers (1969) writes about. A postmodern approach to Ph.D. studies does not mean we have to start from scratch and erase all the history associated with academia. On the contrary, we must build on what is in place and learn from it. As students it is our responsibility to find our own place in the world - to take the knowledge we have to the community. We must never forget that our learning does not end when we leave the walls of the institution, whether we are at the beginning or end of our degrees. The real world is not something we join once we leave school behind. It is where we, as students, live. It is often where we learn the most.

Rogers' (1969) model calls on the student to become both a formal and informal learner. To be successful, the student has to learn in a meaningful way from within the university and from so-called "real life" experiences. Yet it takes a special sort of person to succeed in this type of graduate program. Recall that Lesko (2001) called the postmodern human being a text and a composition, a performance without an essential core. If we consider this the postmodern person and Rogers' model a postmodern approach to graduate studies, we must ask ourselves a very fundamental question. Is the postmodern person equipped to handle the demands of a postmodern doctoral program? 


\section{Communities of Practice}

Campbell: I think Rogers' (1969) model of graduate education addresses many of my concerns about how to "be" a graduate student and it complements the concept of "Communities of Practice" Wenger (1998) described decades later. Communities of practice, according to Wenger (1998), are premised on three critical facets: mutual engagement, joint enterprise, and shared repertoire. At the level of mutual engagement and as a graduate student, I am in the process of negotiating with my peers and professors by contributing to the canon in a complementary or overlapping manner. More immediately this occurs in the classes and eventually will be expressed in the creation and dissemination of a dissertation. It also involves engagement with a larger, academic community or canon of researchers, journal editors, and conference selection committees through conference presentations for eventual publication, such as the one here.

The second requirement for coherence in a community of practice, according to Wenger (1998), was joint enterprise. In a broader sense and as a member of the Faculty of Education community, course selection was an issue that I believed represented joint enterprise, both negotiated and indigenous. Negotiated coursework was done in conjunction with the candidate's supervisor for existing course offerings or in the creation of an independent study course. Individual course content was also tailored to the applicant's field of study in consultation with the course director. Indigenous requirements, on the other hand, existed for course selection, for example a specific methods and seminar course that were required as well as a predetermined number of credits for graduation.

The third requirement for coherence in a community of practice is a shared repertoire, what Wenger (1998) describes as "resources for negotiating meaning" (p. 82) based on a history of engagement and which "remain(s) inherently ambiguous" (p. 83). I began a dictionary of terms, a Cole's Notes if you will, to help me master this new discourse and shared repertoire in which I identified popular phrases and concepts my peers used or I came across in text. I also established a file in which I briefly described the contributions of various educational theorists and philosophers.

Joy: I like the idea of community. I am mindful, however, of what Hobsbawn (2003) called "the invention of tradition." While the academy nostalgically references the medieval Western Europe monastery as its antecedent, it is more culturally relevant perhaps to reference the African madrassahs. However, cultural appropriation of knowledges is a standard of the research tradition. I find myself preoccupied with questions suggested by Britzman (1998): what does knowledge desire; what does knowledge remember; and, what does knowledge forget? And, as a conjure-woman, I have my own question: why?

So, our stories about the emergence of universities in Western Europe during what is called the Dark Ages, infrequently comes to terms with the repressive and brutal nature of those institutions, wherein illuminators were often illiterate scribes who were given pages from different texts to copy into manuscripts so as to safeguard the privileged access of a select few to knowledge. This is the context of labyrinthine storage of manuscripts so brilliantly rendered in semiotician Umberto Eco's (1983) "The Name of the Rose." The Hollywood version of this book wisely depicts a mystery, which stands for what was knowledge in a time of faith. And in the contemporary doctrine of unfettered 
marketing of knowledge, there remains a mystery, a magic, in knowledge production and reproduction, an "unintended consequence," if you like, of the precarious nature of hegemonic negotiations.

Further, recourse to the historical in the context of the academy is more redolent of Simon et al.'s (2000) "memory as difficult return". We are attempting, in the post-colonial moment, to "live in relation to the past." The paradigmatic clash of "The Name of the Rose" is no less violent than are contemporary shifts, though as Foucault (1977) noted, we no longer enact punishment on the body in order to effect ideological conformity. We have the academic protocols of contemporary knowledge currency to "discipline" both apprentices and straying sorcerers, and not just those who go, in popular culture terms, "to the dark side." While conservative academics indict scathingly "revisionist history" in favour of some master narrative of knowledge and its legitimate production, post-colonial theorists are expanding boundaries of what is knowledge, whose knowledge, and how might it be produced. In imagining a different future, we must not fix ourselves so securely to the shoulders of the Western European ancestors that we cannot learn from Walter Benjamin's (1969) allusion, "the angel of history" (see Budgett, 1987). However, as one prescient doctoral candidate-colleague, Melonie Fullick (personal communication, April 10, 2009), noted dryly, we now seem intent on a new orthodoxy in which we "bludgeon students with [preferred] theory."

I know that academics have a childlike glee and self-consciousness about "dressing up" in our elders' clothes at rituals such as convocation. And we beam with pride and satisfaction as we hood "our" Svengali-like creations. It would be interesting to explore to which aspects of the "imposter syndrome" we are giving expression, when we do so (Zorn, 2006). What is the nature of our nervous glances in mirrors and what do we imagine we are seeing? As well, 'history of ideas' approaches tend to naively assume that all can be known, should sufficient documents survive; and there we are mired in sense data, textualized preferably. The contributions of new psychoanalytic work which insist that much may never be known, and/or only known inferentially, would be a good thing to add to the already "complicated" work of "conjuring up social life." Just now I try to unknot Lacan, what might be revealed in talk - and writing — what meaning is given expression in symbolic systems - what are the "signs and wonders"? How sorcerers and apprentices are implicated in this process must be of interest as we seek to live our relations of knowing.

Campbell: What is knowledge then and what is the role of talk in making knowledge. I have tried to show the creation of self through recognition and in relation to Wenger's (1998) Communities of Practice. What I have found is an over-emphasis on a shared repertoire in my experiences as a graduate student. It is in this domain that I have experienced the most direction and in which I feel I have the most active and yet often contested involvement. Perhaps this supports Joy's discussion of knowledge as spoken text.

In class, I became keenly aware of the need for communicative competence and the use of well-constructed, predetermined narratives as central to epistemology. While I originally identified with the "sportive openness" described by Rogers (1969), which he believed fostered curiosity and creativity, I began to worry that this was interpreted as irreverence. No longer did I feel 
comfortable asking a question but instead I found myself using tentative statements and awaiting a reply. This led to questioning the use of dialogue as a means of critical reflection or dialectic.

Kristy: This seems to be a common concern for graduate students. I am reminded of a conversation we had with fellow graduate students while we were planning this paper. The topic under debate was how we saw our role within our programs and what we, as individuals, could contribute. Slowly, each individual admitted to having moments where s/he felt like a fraud - waiting to be found out. The "imposter complex" seems to be a shared graduate student experience. There is comfort in knowing that we share the same anxiety. Perhaps that angst is what makes us a stronger community of practice.

Campbell: Perhaps our shared angst and as a response to the ascribed roles given us, some have chosen to rebel. Wenger (1998) believed that "As a form of participation, rebellion often reveals a greater commitment than does passive conformity" (p. 77). While maybe not evident in physical behaviour or dialogic exchange, rebellion was manifest through our newfound repertoire to critically examine and attempt to deconstruct theorists and pedagogy in an act of resistance and to define who we were. Unfortunately, those discussions, while of great interest and transformative in nature, often occurred external to the "official" classroom. This was perhaps indicative of an ethos that held us unable to meaningfully contribute to, or participate in, a joint enterprise and mutual engagement.

Kristy: These discussions helped shape our views-and community participation - both inside and outside the classroom. In Paradigms we learned that our actions are often shaped by views we did not know we held. Rebellioneven if only visibly manifest outside classroom discussions - becomes part of us and shapes the way we approach our studies.

Campbell: Yes rebellion was important and there was strength and creativity in heterogeneity (Wenger, 1998). This I came to realize was true of our program as the students were multicultural and multilingual. Not only did we come from a number of different disciplines, several students were multilingual and either new Canadians or present on a student visa. This led me to question the nature of engagement. I came to understand that engagement was premised on the presupposition of talk as knowledge, a form of institutional and linguistic assimilation, as our classes were conducted in one language (English) and within implicit and explicit academic, reified codes of behaviour.

Engagement also seemed tempered with issues of shame and face. Frequent discussions with my peers converged on how to participate without appearing overbearing to others while at the same time disinterested or unprepared for class. A colleague and I also realized that after having taken coursework on a number of theorists, we now feel like we have come to a deeper or richer level of understanding about education studies, perhaps more so than students in the Masters program. As we participated in class, however, we found ourselves more consciously aware of how our peers framed their questions and the paradigmatic beliefs evident in their level of engagement and hesitant to share our own views, perhaps adopting a negative face saving technique of silence or truncated participation. Wenger's (1998) theoretical model encouraged me to recognize 
and valorize the heterogeneity of doctoral communities and understand that participation was "inherently partial" and varied.

\section{Conclusion}

Joy: I think of the work I do as a potentially ethical encounter with the Other in knowledges, doctoral candidates, colleagues, the social world, and in myself. Todd (2003) urges that I take up these encounters. I also follow Avery Gordon (1997) who tells us that social analysis is mandated to conjuring, "a particular form of calling up and calling out the forces that make things as they are in order to fix and transform a troubling situation" (p. 22). This is a place, for me, of spiritual centring, since as with all "conjure women", I can only work with what is. When I speak of conjuring with what is, I am not speaking only of what empiricists call sense data. "That life is complicated is a fact of great analytical importance", according to Williams (1991, p. 10). Further, as Toni Morrison (1989) argues, "invisible things are not necessarily not-there" (p. 11). So, this wand business is something in the way of Taussig's (in Gordon, 1997, p. 20) "sympathetic magic" in that ideally the representation-as-knowledge is imbued "with the power of the represented."

Campbell: To claim that power, we have come to realize that we are on a quest for transformation and must focus on the process, for example levels of engagement, and not the product. This understanding began for me in our summative Paradigms project, where I described how "Individuals are always in the act of becoming. The nature of knowledge and how individuals come to know is dialogic, does not require consensus, and can lead to multiple understandings."

Joy: Rose (1994) might consider this process and this manuscript an act of "polyvocal conversation."

Campbell: Indeed it is a polyvocal conversation which Kristy, Joy, and I are seeking to animate here. At the same time, the act of becoming, belonging, and recognition can be a great source of cognitive dissonance that a graduate student must be able to tolerate and which professors should encourage - in themselves as well.

Joy: There is the possibility for a more egalitarian process of academic knowledge production - an epistemological and praxis break called into being by a new configuration of professor-student-knowledge-power social relations. Further, we might discover that we can apply Butler's (1999) notion of performativity here with respect to being sorcerers and apprentices. As well, we sorcerers have remained curiously silent about the utility of theories of remembrance in thinking about the Ph.D.-getting process. Such work could open up a vastly adjusted notion of the Ph.D. process and relations between professors and doctoral candidates.

Kristy: What can we do, as graduate students in this new relationship, to assume a greater role?

Joy: In the relative absence of the professor-sorcerer, the apprentice-doctoral candidate is quite capable of applying what $\mathrm{s} /$ he has learned perhaps in spite of the professor-master. This requires two things: the encouragement of the master and the confidence of the apprentice, both of which can only ensue in adjustments to the traditional academic structure of knowledge production and 
reproduction. The gift of the wand is a stolen gift and deeply flawed; apprentices should take it up with great caution.

\section{Acknowledgments}

Previous drafts of this paper have been presented under the title, "Not only the sorcerer's apprentice? Reconjuring the $\mathrm{PhD}$ " in May 2008 at the "York University Graduate Conference in Education" and in July 2008 at Windsor University's "Provoking Research Provoking Communities" conference. The authors would like to thank session participants for sharing their thoughts and insights. They would also like to thank an anonymous reviewer for providing insightful comments and encouragement.

\section{References}

Benjamin, W. (1969). Illuminations (H. Arendt, Ed.). (H. Zohn, Trans.). New York: Shocken.

Britzman, D. P. (1998). Lost subjects, contested objects: Toward a psychoanalytic inquiry of learning. New York: State University of New York Press.

Budgett, G. (1987). The angel of history. Retrieved from http://www.arts.ucsb.edu/faculty/budgett/angelus.html

Butler, J. (1999). Gender trouble: Feminism and the subversion of identity. New York: Routledge.

Deaf Performing Artists Network (2009). Waiting on the world to change. Retrieved from http://www.d-pan.com/index.php?option=com_content\&task=view\&id=35\&Itemid=35

Disney. (2009). Mickey mouse. Retrieved from http://disney.go.com/vault/archives/characterstandard/mickey/feature/feature.html

Dlamini, S. N. (2006). Inkumbulo as remembering, communing, and praxis: Retelling the stories of transformation and learning. International Education, 36(1), 32-45.

Eco, U. (1983). The name of the rose. Orlando, Florida: Harcourt Brace.

Foucault, M. (1977). Discipline \& punish: The birth of the prison. United States: Random House.

Gordon, A. (1997). Ghostly matters: Haunting and the sociological imagination. Minneapolis US: University of Minnesota Press.

Graveline, F. J. (1998). CircleWorks: Transforming eurocentric consciousness. Halifax, Nova Scotia: Fernwood Books.

Haig-Brown, C. \& Dannenmann, K. (2002). A pedagogy of the land: Dreams of respectful relations. McGill Journal of Education, 37(3), 451-468.

Hobsbawn, E. (2003). Introduction: Inventing traditions. In E. Hobsbawn \& T. Ranger (Eds.), The invention of tradition (pp. 1-14). Cambridge, UK: Cambridge University Press.

King, T. (2003). The truth about stories: A native narrative. Toronto: Ananasi.

Kirby, S. L., Greaves, L. \& Reid, C. (2006). Experience research social change: Methods beyond the mainstream $\left(2^{\text {nd }}\right.$ ed.). Peterborough, Ontario: Broadview Press.

Lave, J. (1990). The culture of acquisition and the practice of understanding. In J Stigler, R. Sheder, \& G. Herdt (Eds.), Cultural psychology (pp. 309-327). Cambridge, UK: Cambridge University Press.

Lesko, N. (2001). Act your age! A cultural construction of adolescence. New York: Routledge Falmer.

Morrison, T. (1989). Unspeakable things unspoken: The afro-american presence in american literature. Michigan Quarterly Review, 28(1), 1-34.

Nicolas, J. (2008). Researchers for tomorrow. University Affairs. Retrieved from http://www.universityaffairs.ca/researchers-for-tomorrow.aspx\#

Nyquist, J. \& Wulff, D. H. (2002). Recommendations from national studies on doctoral education. Re-Envisioning the Ph.D. Retrieved from http://www.grad.washington.edu/envision/project_resources/national_recommend.html 
Rogers, C. R. (1969) Freedom to learn. Ohio: Charles E. Merrill Publishing Company.

Rose, T. (1994). Black noise: Rap music and black culture in contemporary America. Hanover, New Hampshire: Wesleyan University Press

Simon, R. I., Rosenberg, S. \& Eppert, C. (2000). Introduction, between hope and despair: The pedagogical encounter of historical remembrance. In R. I. Simon, S. Rosenberg \& C. Eppert (Eds.), Between hope and despair: Pedagogy and the remembrance of historical trauma (pp. 1-8). United States of America: Rowman \& Littlefield Publishers.

Todd, S. (2003). Learning from the other: Levinas, psychoanalysis, and ethical possibilities in education. Albany, New York: State University of New York Press.

Turk, J. (Ed.). (2008). Universities at risk: How politics, special interests and corporatization threaten academic integrity. Halifax, Nova Scotia: Formac Publishing.

Wenger, E. (1998). Communities of practice: Learning, meaning, and identity. Cambridge, MA: Cambridge University Press.

Williams, P. (1991). The alchemy of race and rights. Cambridge, MA: President and Fellows of Harvard College.

Zorn, D. (2006, May). The politics of imposter feelings in higher education. Symposium conducted at Canadian Society for Studies in Education Annual Meeting of the 2006 Congress for the Humanities and Social Sciences, York University, Toronto, Canada.

Kristy Buccieri is a Ph.D. candidate in the Faculty of Education at York University in Toronto, Ontario. Her research has focused on youth homelessness, particularly around issues of substance use, harm reduction, and access to healthcare. Currently she is researching the spatial dynamics of homelessness and the informal learning that occurs while living on the street.

Campbell McDermid is a Ph.D. candidate in the Faculty of Education at York University and a professor at George Brown College in Toronto, Ontario. He has extensive experience researching and educating students in American Sign-Language-English Interpretation programs. His current research engages ASL-English interpreters through narrative inquiry.

Joy Mannette is an Associate Professor in the Faculty of Education at York University in Toronto, Ontario. Her research interests include cross-cultural ways of knowing, community organizing for change, cross-cultural learning, university experiences of racialized students, law, policy and ethics, and new approaches in qualitative research. She is known for her work on the Marshall Inquiry and has also lived and researched in the Mohlakeng township west of Johannesburg, South Africa. 